\title{
Application of Analytic Hierarchy Process for Assessing Sustainable Development among Underprivileged Communities
}

\author{
Lazim Abdullah $^{1} \&$ Jin Yong Pang ${ }^{1}$ \\ ${ }^{1}$ School of Informatics and Applied Mathematics, Universiti Malaysia Terengganu, Malaysia \\ Correspondence: Lazim Abdullah, School of Informatics and Applied Mathematics, Universiti Malaysia \\ Terengganu, Kuala Terengganu, 21030 Malaysia. Tel: 60-9-668-3335. E-mail: lazim_m@umt.edu.my
}

Received: July 10,2016 Accepted: August 10, $2016 \quad$ Online Published: September 27, 2016
doi:10.5539/jsd.v9n5p70
URL: http://dx.doi.org/10.5539/jsd.v9n5p70

\begin{abstract}
One of the purposes of sustainable development assessment is to identify the most importance criteria and sub-criteria of sustainable development that have the most significant contribution to the local community. To date, few studies have inquired into qualitative methods to assess these criteria and sub-criteria. In response to this gap in the literature, we propose an application of the analytic hierarchy process (AHP) method to prioritize thirteen sub-criteria of sustainable development among underprivileged community of Setiu Wetlands Terengganu. Consistency ratio and weighted geometric mean are the two important computation steps of the AHP prior to proposing global weights of sub-criteria. The computational results indicate that 'Education' is the most important sub-criteria with $15.4 \%$ of global weight. At the other extreme 'global economic partnership' is the least important sub-criteria for this group of community. The outcome of the proposed method is a weight of sustainability for all sub-criteria which offers a guide to government in identifying the appropriate action for uplifting the community quality of life.
\end{abstract}

Keywords: sustainable development, analytic hierarchy process, setiu wetlands, underprivileged community

\section{Introduction}

Sustainable development has emerged in 1987 when the World Commission of Environment and Development released its definition through The Bruntdland Report. This report defines sustainable development as the improvement that meet the needs of the present without compromising the ability of future generations to meet their own needs. The definition has been extended to enclose three main criteria which are economic development, social development and environmental development (Parkin et al., 2003). Some literature suggests that all the three development criteria are taken together and related to each other to become the basis of economic development (Ihlen \&Roper, 2014). In the context of Malaysia, social development mainly focuses on several sub-criteria which could satisfy the varied needs of the community, for example health, governance and education as the basic requirements. The economic development has received a lot of emphasis because it boosts significant developments in the well-being of communities. The key concepts are related to sustaining economic growth, efficiency and competitiveness, flexibility and stability, increases of production, employment and international trade. Meanwhile, environmental development is forced to conserve and recycle resources and maintain the environmental systems (MPC, 2010). The inclusion of criteria and sub-criteria in defining sustainable development are consistent with the definition of the UK government where the ultimate aim of sustainable development is providing people with a better quality of life (Choi \& Ahn, 2013). These interconnected criteria of sustainable development have attracted many researchers to investigate its concepts at regional or country levels using various methods and approaches.

In Malaysia, a research was conducted by Saadation et al., (2011) to look at policies, plans and assessment tools in sustainable development using the archival method. The purpose of their research was to highlight Malaysia sustainable development initiatives into two aspects of micro scale and mega scale depending on the need of a local level assessment approach. These observations and survey approaches conclude that Malaysia has already developed comprehensive assessment approaches and indicators for national, state, and district levels. In other research, Jalil (2010) focuses on a small aspect of environmental protection of sustainable development of a proper management of household waste. A methodology based on descriptive analysis has been used to discuss how household waste in Malaysia could be converted into vermicompost. Azmi \& Romle (2015), examine the 
implementation of the green city concept that can enhance the quality of life and assure sustainability for present and future in Malaysia. The exploratory study design has been used to conduct this research where secondary data such as journals, media, case studies, books, websites, and government publications were the main sources of information.

In can be seen that most of the investigations about sustainability in Malaysia are conducted using surveys and review methods. Very little research investigates the sustainable development in Malaysia from the perspective of multi-criteria decision making despite the multiple criteria characteristics that clearly attached to the definition of sustainable development. Furthermore, it seems that sustainable development is only relevant at national level where as sustainable development in a small remote region has been neglected. Unlike the previous studies, this paper intends to investigate the concepts of sustainable development of a small underprivileged community with very specialized socio-economic activities in Terengganu Malaysia. Specifically, this paper aims to propose global weights for sub-criteria of sustainable development at the Setiu Wetlands Terengganu using the decision making method of analytic hierarchy process (AHP). The AHP method was developed by Saaty in 1977 as a model which can be used to solve multi-criteria decision-making problems. This model provides a means of decomposing the problem into a hierarchy of sub-problems which can be easily interpreted. Literature review about the applications of AHP to related sustainable development research is provided in the following section.

\section{Literature Review}

The AHP method is a theory of measurement using the concept of pairwise comparisons. This method has been applied worldwide to diverse applications including sustainable development. Reviews of the applications of AHP to sustainable development are summarized in Table 1.

Table 1. Various applications of the AHP in sustainable development

\begin{tabular}{ll}
\hline Research articles & Contributions \\
\hline Cuadrado et al., (2016) & $\begin{array}{l}\text { An AHP based Multi-Criteria Decision-Making methodology has been } \\
\text { applied in improvements of sustainability in construction industry. Three } \\
\text { case studies were compared using this method. }\end{array}$
\end{tabular}

Prakash et al., (2016) The AHP was used to assign weights to the indicators and sub-indices of quality of life. The assessment uses 10 sub-indices constructed using 54 indicators in India.

Veisi, et al., (2016) The AHP was employed to determine the critical factors affecting the priority of alternatives of sustainability in agriculture and food systems in Iran.

Al-Atawi et al. (2016) The AHP has been applied in assessment of sustainable transport strategies for Tabuk City in the Saudi Arabia. A number of transport policies and strategies have been tested for inclusion in the developed system.

Yagmur (2016)

The AHP has been employed to determine a priority analysis in relation to localization equipment for a thermal power plant.

Verma et al., (2016) The AHP based quantitative framework has been used to help a logistics provider rank prospective partner original equipment manufacturer companies with the view of optimising its business development approach in the fast moving consumer goods sector. Key decision making factors are identified using primary and secondary research. This framework is used to prioritise their business developments efforts and to focus on the right clientele to achieve profitable and sustainable growth.

Shen et al., (2015). The AHP has been used to evaluate the competitive priorities of green supply chain management criteria in the case of the Indian mining industry.

Abba et al., (2013) The AHP technique was used to structure and compute the judgments of stakeholders on the environmental impacts of solid waste disposal in Johor Bahru Malaysia. The researcher used the a software to develop and assess results of stakeholder's judgments.

Aminbakhsh et al., The AHP has been applied to safety risk assessment during the planning 
Aldegheishem (2014) and budgeting of construction projects. To adequate prioritization of safety risks, a safety risk assessment framework was presented based on the theory of cost of safety model and the AHP. With the help of a framework, decision makers able to determine the adequate accident/injury prevention investments.

The AHP was applied to evaluate the urban sustainable development for Riyadh city. The indicators of sustainability were defined based on the urban level and segregated into three indexes such as level of development, development coordination extent, and development potential.

It can be seen that the variations are not only happened in applications, but also in the methods of AHP. Since its inception in 1987, the AHP method has been developed in various versions, especially in the way of computing aggregation and consistency ratio. In this paper, the new version of AHP specifically tailored for group decision making is adapted. Detailed procedures of the method are described in Section 3.

\section{Procedure of AHP with Aggregation of Individual Judgement}

It is known by most of the enthusiast in decision making that the AHP is a structured multi-attribute or multi-criteria decision making method. The advantage of AHP is able to check and reduce the inconsistency of judgments of experts. This is especially true for the case of more than one or many experts are invited to make a judgment. Therefore, the following procedure of AHP introduces two innovations within the group decision making environment. First, Alonso and Lamata (2006) formulae is used in the computation of consistency ratio. Second is the weighted geometric mean is introduced instead of the arithmetic mean in aggregating the pairwise comparison matrices. The procedure of AHP is described as follows:

\section{Step 1: Identify decision problem}

Decompose the problem into a hierarchy structure which consists of goal, criteria and sub-criteria. Structuring the decision problem as a hierarchy is a basic to the process of AHP.

\section{Step 2: Data collection via expert rating}

Experts rate the criteria and sub-criteria corresponding to the hierarchy structure (Step 1) using a qualitative scale in a questionnaire in which, the questions are arranged in the pairwise comparison. Experts rate the comparison as equal, marginally strong, strong, very strong and extremely strong, according to the scale in Table 2.

Table 2. Gradation scale for qualitative and quantitative comparison of alternatives

\begin{tabular}{|c|c|c|}
\hline $\begin{array}{l}\text { Intensity of } \\
\text { Importance }\end{array}$ & Definition & Explanation \\
\hline 1 & Equal Importance & $\begin{array}{l}\text { Two activities contribute equally to the } \\
\text { objective }\end{array}$ \\
\hline 2 & Weak or slight & Intermediate values to reflect fuzzy inputs \\
\hline 3 & Moderate importance & $\begin{array}{l}\text { Experience and judgement slightly favor one } \\
\text { activity over another }\end{array}$ \\
\hline 4 & Moderate plus & Intermediate values to reflect fuzzy inputs \\
\hline 5 & Strong importance & $\begin{array}{l}\text { Experience and judgement strongly favor one } \\
\text { activity over another }\end{array}$ \\
\hline 6 & Strong plus & Intermediate values to reflect fuzzy inputs \\
\hline 7 & Very strong importance & $\begin{array}{l}\text { An activity is favored very strongly over } \\
\text { another; }\end{array}$ \\
\hline 8 & Very, very strong & Intermediate values to reflect fuzzy inputs \\
\hline 9 & Extremely strong importance & $\begin{array}{l}\text { The evidence favoring one activity over } \\
\text { another is of the highest possible order of } \\
\text { affirmation }\end{array}$ \\
\hline
\end{tabular}


Reciprocals

of above
If activity $i$ has one of the above non-zero numbers assigned to it when compared with activity $j$, then $j$ has the reciprocal value when compared with $i$

(Source: Saaty, 2008)

A reasonable assumption

Step 3: Construct decision matrix

A square matrix is constructed by inserting all the pairwise comparisons of the criteria used. The diagonal elements of the matrix are 1 . If the value of element $(i, j)$ is more than 1 , which means the criterion in the $i$ th row is better than criterion in the $j$ th column. Meanwhile, the reciprocal of the $(i, j)$ element of the matrix is $(j, i)$ element. The general structure of decision matrix is given in equation (1). )

$$
A=\left(\begin{array}{cccc}
1 & a_{12} & \cdots & a_{1 n} \\
\frac{1}{a_{12}} & 1 & \cdots & a_{2 n} \\
\vdots & \vdots & \ddots & \vdots \\
\frac{1}{a_{1 n}} & \frac{1}{a_{2 n}} & \cdots & 1
\end{array}\right)
$$

A condition of multiplicative reciprocity $A_{i j}=\frac{1}{A i j}, \forall i, j$ holds.

Step 4: Priority of criteria for individual expert and consistency ratio

Evaluate the consistency of the square matrix of order $N$. The comparison results that constructed by the experts are subjective. Consistency ratios $(C R)$ are calculated based on the respective comparison results. The pairwise comparison matrix may be re-examined when the $C R$ fails to achieve a require level. $\alpha$ is introduced as a level of consistency needed to adapt the cut-off value $(C R<\alpha)$. Saaty's rule of thumb is to accept only judgment matrices with $C R<0.1$. Prior to calculating $C R$, there is a need to calculate the priorities of a pairwise NxN comparison matrix $A_{i j}$ using the row geometric mean method. The elements of matrix $A_{i j}$ is calculated using equation 2 .

$$
r_{i}=\exp \left[\frac{1}{N} \sum_{j=1}^{N} \ln \left(A_{i j}\right)\right]=\left(\prod_{j=1}^{N} A_{i j}\right)
$$

The elements of normalized matrix are calculated using equation 3.

$$
p_{i}=\frac{r_{i}}{\sum_{i=1}^{N} r_{i}}
$$

where $p_{i}$ is the priorities of the criteria

The following steps show the calculation of $C R$ :

(a) The Principal Eigenvalue $\left(\lambda_{\max }\right)$ is calculated from the summation of products between each element of Eigen vector (priorities) and the sum of columns of the pairwise comparison matrix. (see equation (4)). 


$$
\lambda_{\max }=\sum_{j=1}^{N} p_{i} a_{i j}
$$

where $p_{i}$ are the priorities of the criteria, and $a_{i j}$ is sum of columns of the pairwise comparison matrix.

(b) The consistency ratio, $C R$ is calculated using Alonso and Lamata (2006) equation.

The Saaty's $C R$ threshold is too restrictive due to the standard deviation of the consistency index for randomly generated matrices being relatively small. When $n$ increases, Saaty results are outside the accepted consistency. Therefore, Alonso and Lamata's method (2006) suggests a formula that adaptability in the acceptance criterion and the simplicity of the index. The formula to calculate $C R$ is given in equation (5).

$$
C R=\frac{\lambda_{\max }-N}{2.7699 N-4.3513-N}
$$

Step 5: Aggregation of individual judgement

There are several possible ways to aggregate information when more than one individual expert is participating in the decision process. According to Forman \& Peniwati (1998), there are two useful aggregation methods. First is aggregating of individual judgment (AIJ) and the second is aggregating of individual priorities. As to reduce information losses during the analysis, the method AIJ is applied in this research. The AIJ constructs an aggregated decision matrix $C_{i j}$ combines all $k$ participants' input to get the aggregated group result. In other words, the use of AIJ means that the group is assumed to be a synergistic unit. In this research, the individual expert's weight $w_{k}$ is considered to be equal. The calculation of $C_{i j}$ using the weighted geometric mean is shown in equation (6).

$$
C_{i j}=\exp \frac{\sum_{k=1}^{N} w_{k} \ln A_{i j(k)}}{\sum_{k=1}^{N} w_{k}}
$$

where $w_{k}$ is the weight of $k$ th expert

$A_{i j(k)}$ is the pairwise comparison matrix of $k$ th expert

Step 6: Calculate local priorities

With the aggregated decision matrix $C_{i j}$, local priorities of criteria and sub-criteria are calculated by applying the

geometric mean method. The elements of matrix $C_{i j}$ is calculated using equation (7).

$$
r_{i}=\exp \left[\frac{1}{N} \sum_{j=1}^{N} \ln \left(C_{i j}\right)\right]=\left(\prod_{j=1}^{N} C_{i j}\right)
$$

Normalization of elements is calculated using eq (8)

$$
p_{i}=\frac{r_{i}}{\sum_{i=1}^{N} r_{i}}
$$


where $p_{i}$ are the priorities of the criteria and sub-criteria

Since, the $C R$ of every individual expert is less than $\alpha$ in Step 4, then the $C R$ for aggregated decision matrix $C_{i j}$ will also need to be less than $\alpha$ prior to continuing Step 7 .

Step 7: Calculate global priorities

The priority of each criterion and sub-criterion is calculated by Row Geometric Mean Method (Escobar \& Moreno-jiménez, 2007). Global priorities are calculated from the top of hierarchy by multiplying the local priorities of sub-criteria with the priority of their corresponding criteria at the level above. It is shown in Eq (9).

$$
p_{G}=p_{i(\text { criteria })} \times p_{i(\text { sub-criteria })}
$$

The seven-step procedure is implemented to a case study where a group of experts is invited to make judgement.

\section{Case Study}

\subsection{Location}

A case study has been carried out at Setiu Werlands Teregganu, one of the districts in Peninsular Malaysia. Setiu Wetlands are sited in the north part of Terengganu, Malaysia and it belongs to the districts of Setiu which is placed along the east coast of Peninsular Malaysia. With latitude, N05.4038 ${ }^{0}$ and longitude, E102:4302 ${ }^{0}$, Setiu Wetlands consisted of Setiu River, lagoon with various islands, and facing the South China Sea. Majority of the Setiu Wetlands community is fishermen which depend on fish catchment to earn a living. They also produce the well-known Terengganu anchovies, fish-crackers and shrimp paste as a side income. The fishermen are considered as underprivileged communities because they are deprived of social and economic condition of some fundamental right of society.

\subsection{Criteria and Sub-Criteria}

In addition to the three criteria, United Nation Department of Economic and Social Affairs (2006) released the framework of a set of criteria and sub-criteria of sustainable development. The framework contains 13 sub-criteria which are 5 sub-criteria for environment, another 5 sub-criteria for social and the remains for economic. The sub-criteria in the environment criterion are atmosphere, biodiversity, land, freshwater and sea and coastal area. Meanwhile, sub-criteria in social criterion are poverty, education, health, governance and demographic whereas the sub-criteria in economic criterion are economic development, global economic partnership and consumption and production pattern. Three criteria and their respective sub-criteria are shown in Figure 1. 


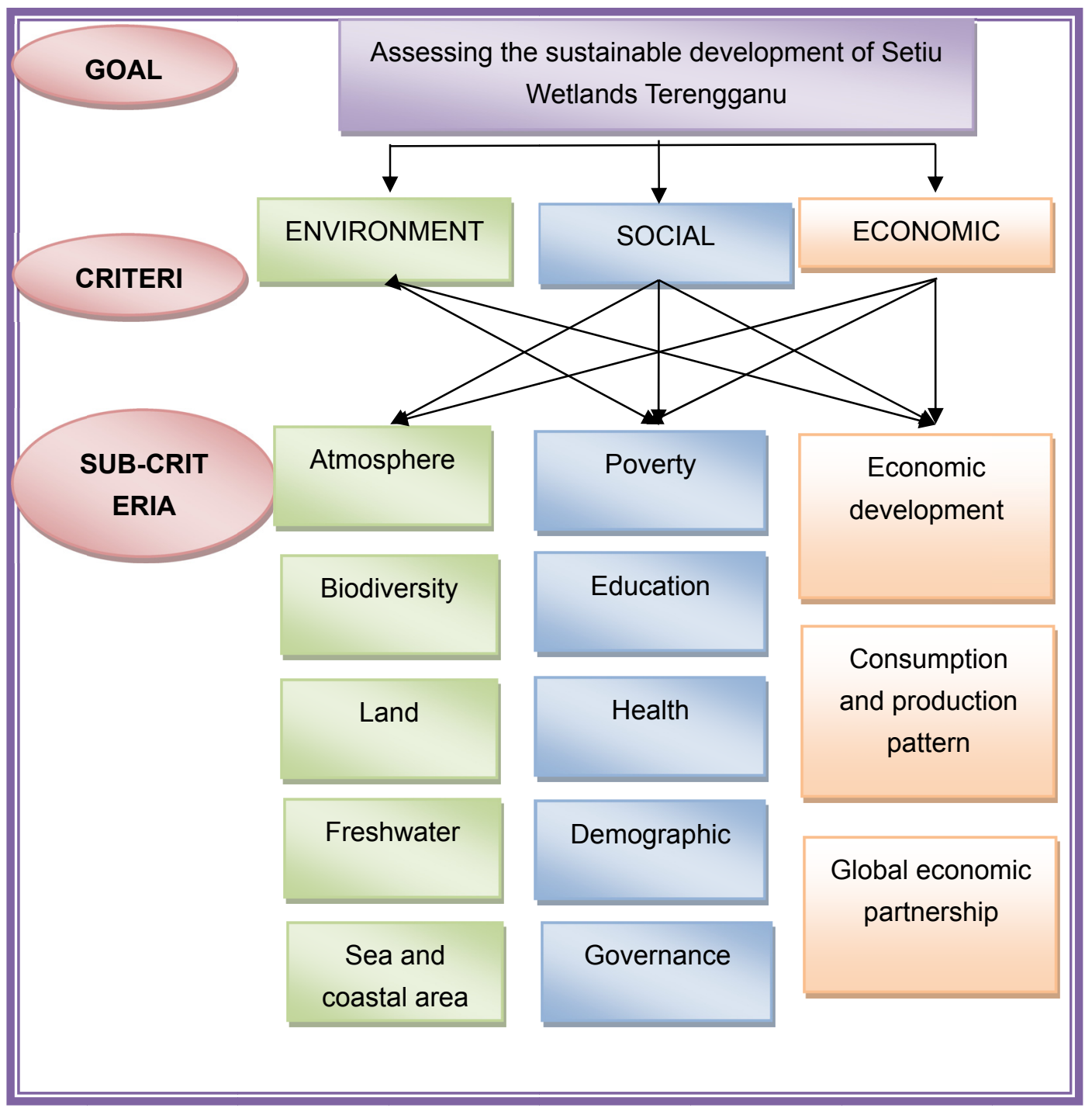

Figure 1. Hierarchical model

\subsection{Computation}

The subjective evaluations are converted into numerical values and rank each sub-criterion on a numerical scale. The data from the questionnaire are inserted into the procedure of the AHP. The implementation of AHP to the case study is described as follows.

Step 1: Identify criteria, sub-criteria and hierarchy model.

The AHP hierarchy model, criteria and sub-criteria that needed to assess the sustainable development are identified (see Figure 1). The problem is decomposed into a hierarchy structure which consists of goal, criteria and sub-criteria.

\section{Step 2 : Linguistic Data Collection}

Linguistic data collection is made using a questionnaire based on the linguistic definitions defined in Table 2.

\section{Step 3: Construct pairwise comparison matrix}

Pairwise comparison matrix is constructed based on judgement made by experts. The matrix $A$, for example, is constructed based on the judgement made by Expert 1. 
$A=\left[\begin{array}{ccc}1 & 2 & 3 \\ \frac{1}{2} & 1 & 3 \\ \frac{1}{3} & \frac{1}{3} & 1\end{array}\right]$

Step 4: Priority of criteria for individual expert and consistency ratio

The calculation of $C R$ to check the consistency of judgment is shown as below,

$r_{i}=\left(\prod_{j=1}^{N} a_{i j}\right)^{\frac{1}{N}}=\left(\left[\begin{array}{c}1 \\ \frac{1}{2} \\ \frac{1}{3}\end{array}\right] \cdot\left[\begin{array}{l}2 \\ 1 \\ \frac{1}{3}\end{array}\right] \cdot\left[\begin{array}{l}3 \\ 3 \\ 1\end{array}\right]\right)^{\frac{1}{3}}=\left[\begin{array}{c}6 \\ \frac{3}{2} \\ \frac{1}{2}\end{array}\right]^{\frac{1}{3}}=\left[\begin{array}{l}1.8171 \\ 1.1447 \\ 0.4807\end{array}\right]$

$p_{i}=\frac{r_{i}}{\sum_{i=1}^{N} r_{i}}=\left[\begin{array}{l}1.8171 \\ 1.1447 \\ 0.4807\end{array}\right] \div 3.4425=\left[\begin{array}{l}0.5278 \\ 0.3325 \\ 0.1397\end{array}\right]$

For easy interpretation, the priorities are converted to nearest percentages.

Consistency ratio is calculated as follows:

$\lambda_{\max }=0.52781+\frac{1}{2}+\frac{1}{3}+0.33252+1+\frac{1}{3}+0.1397(3+3+1)=3.0539$

Alonso and Lamata's formula (equation (5)) is applied to calculate $C R$.

$C R=\frac{\lambda_{\max }-N}{2.7699 N-4.3513-N}=\frac{3.0539-3}{2.7699(3)-4.3513-3}=0.056$

Similarly, $C R$ from other experts for all criteria and sub-criteria are also computed. All $C R s$ fulfil the requirement $C R<0.1$, thereby judgments made by experts are consistent and pairwise comparison matrices are acceptable.

The similar calculations are applied for pairwise comparison of other criteria and sub-criteria. Table 3, Table 4, Table 5 and Table 6 show the summary of the priorities of individual of experts and consistency ratio $(C R)$ with respect to criteria and sub-criteria.

Table 3. Priorities of individual of experts based on criteria

\begin{tabular}{lllll}
\hline Decision makers & Environment & Social & Economic & CR \\
\hline Expert 5 & $17.2 \%$ & $72.6 \%$ & $10.2 \%$ & 0.030 \\
Expert 4 & $32.7 \%$ & $41.3 \%$ & $26.0 \%$ & 0.056 \\
Expert 3 & $32.7 \%$ & $41.3 \%$ & $26.0 \%$ & 0.056 \\
Expert 2 & $41.6 \%$ & $45.8 \%$ & $12.6 \%$ & 0.010 \\
Expert 1 & $52.8 \%$ & $33.3 \%$ & $14.0 \%$ & 0.056 \\
\hline
\end{tabular}


Table 4. Priorities of individual of experts based on sub-criteria of environment

\begin{tabular}{lllllll}
\hline Decision makers & Atmosphere & Biodiversity & Land & Freshwater & Sea And Coastal Area & CR \\
\hline Expert 5 & $40.0 \%$ & $6.4 \%$ & $39.3 \%$ & $9.8 \%$ & $4.5 \%$ & 0.067 \\
Expert 4 & $26.2 \%$ & $13.2 \%$ & $13.2 \%$ & $33.6 \%$ & $13.7 \%$ & 0.080 \\
Expert 3 & $67.0 \%$ & $2.8 \%$ & $9.5 \%$ & $9.5 \%$ & $11.1 \%$ & 0.098 \\
Expert 2 & $48.1 \%$ & $28.6 \%$ & $12.6 \%$ & $3.3 \%$ & $7.4 \%$ & 0.091 \\
Expert 1 & $15.2 \%$ & $21.8 \%$ & $16.4 \%$ & $24.9 \%$ & $21.6 \%$ & 0.071 \\
\hline
\end{tabular}

Table 5. Priorities of individual of experts based on sub-criteria of social

\begin{tabular}{lllllll}
\hline Decision makers & Poverty & Education & Health & Governance & Demographic & CR \\
\hline Expert 5 & $3.1 \%$ & $42.2 \%$ & $10.4 \%$ & $30.9 \%$ & $13.3 \%$ & 0.083 \\
Expert 4 & $31.8 \%$ & $19.0 \%$ & $34.6 \%$ & $7.3 \%$ & $7.3 \%$ & 0.059 \\
Expert 3 & $4.4 \%$ & $58.2 \%$ & $18.3 \%$ & $16.3 \%$ & $2.9 \%$ & 0.084 \\
Expert 2 & $11.0 \%$ & $5.9 \%$ & $24.1 \%$ & $3.7 \%$ & $55.3 \%$ & 0.094 \\
Expert 1 & $3.9 \%$ & $34.7 \%$ & $31.2 \%$ & $17.7 \%$ & $12.6 \%$ & 0.098 \\
\hline
\end{tabular}

Table 6. Priorities of individual of experts based on sub-criteria of economic

\begin{tabular}{lllll}
\hline $\begin{array}{l}\text { Decision } \\
\text { makers }\end{array}$ & $\begin{array}{l}\text { Economic } \\
\text { Development }\end{array}$ & $\begin{array}{l}\text { Global } \\
\text { Partnership }\end{array}$ & $\begin{array}{l}\text { Economic } \\
\text { Consumption And Production }\end{array}$ & $\begin{array}{l}\text { CR } \\
\text { Pattern }\end{array}$ \\
\hline Expert 5 & $63.7 \%$ & $10.5 \%$ & $25.8 \%$ & 0.040 \\
Expert 4 & $50.0 \%$ & $25.0 \%$ & $25.0 \%$ & 0.000 \\
Expert 3 & $47.6 \%$ & $7.2 \%$ & $45.2 \%$ & 0.030 \\
Expert 2 & $47.6 \%$ & $7.2 \%$ & $45.2 \%$ & 0.030 \\
Expert 1 & $67.4 \%$ & $22.6 \%$ & $10.1 \%$ & 0.090 \\
\hline
\end{tabular}

Step 5: Aggregation

Once the judgment of every experts is consistent, the next step is aggregating the individual judgment. Since the individual expert's weight is considered as equal, the weight of $k$ th expert is $w_{k}=0.2$. The pairwise comparison matrix of every expert is aggregated using Weighted Geometric mean (WGM) method using equation (6).

For example, the aggregated decision matrix for the criteria is calculated as.

$$
\begin{gathered}
c_{i j}=\frac{\left(0.2 \cdot \ln \left[\begin{array}{ccc}
1 & 2 & 3 \\
\frac{1}{2} & 1 & 3 \\
\frac{1}{2} & \frac{1}{3} & 1
\end{array}\right]+0.2 \cdot \ln \left[\begin{array}{ccc}
1 & 1 & 3 \\
\frac{1}{1} & 1 & 4 \\
\frac{1}{3} & \frac{1}{4} & 1
\end{array}\right]+0.2 \cdot \ln \left[\begin{array}{lll}
1 & 1 & 1 \\
1 & 1 & 2 \\
1 & \frac{1}{2} & 1
\end{array}\right]+0.2 \ln \left[\begin{array}{lll}
1 & 1 & 1 \\
1 & 1 & 2 \\
1 & \frac{1}{2} & 1
\end{array}\right]+0.2 \ln \left[\begin{array}{ccc}
1 & \frac{1}{5} & 2 \\
5 & 1 & 6 \\
\frac{1}{2} & \frac{1}{6} & 1
\end{array}\right]\right)}{0.2+0.2+0.2+0.2+0.2} \\
=\ell^{\left[\begin{array}{ccc}
0 & -0.1833 & 0.5781 \\
0.1833 & 0 & 1.1326 \\
-0.5781 & -1.1326 & 0
\end{array}\right]}
\end{gathered}
$$

then,

$$
C_{i j}=\left[\begin{array}{ccc}
1 & 0.8325 & 1.7826 \\
1.2011 & 1 & 3.1037 \\
0.5610 & 0.3222 & 1
\end{array}\right]
$$


Step 6: Calculate local priorities

Similarly, the aggregated decision matrices for all sub-criteria are calculated

With the aggregated decision matrix $C_{i j}$, local priorities of criteria are calculated using equation (7) and equation

(8). For example, local priorities for the three criteria are calculated as,

$$
\begin{gathered}
r_{i}=\left(\left[\begin{array}{c}
1 \\
1.2011 \\
0.5610
\end{array}\right] \cdot\left[\begin{array}{c}
0.8325 \\
1 \\
0.3222
\end{array}\right] \cdot\left[\begin{array}{c}
1.7826 \\
3.1037 \\
1
\end{array}\right]\right)^{\frac{1}{3}}=\left[\begin{array}{l}
1.4840 \\
3.7279 \\
0.1806
\end{array}\right]^{\frac{1}{3}}=\left[\begin{array}{l}
1.1406 \\
1.5506 \\
0.5653
\end{array}\right] \\
p_{i}=\left[\begin{array}{c}
1.1406 \\
1.5506 \\
0.5653
\end{array}\right] \div 3.2565=\left[\begin{array}{l}
0.3503 \\
0.4762 \\
0.1736
\end{array}\right]
\end{gathered}
$$

The local priorities are shown in Table 7.

Table 7. Aggregated priorities of criteria

\begin{tabular}{ccccc}
\hline & Environment & Social & Economic & CR \\
\hline Group decision & $35.0 \%$ & $47.6 \%$ & $17.4 \%$ & 0.016
\end{tabular}

Similarly, aggregated priorities of sub-criteria are summarised in Table 8, Table 9, and Table 10.

Table 8. Aggregated priorities based on sub-criteria of Environment

\begin{tabular}{ccccccc}
\hline & Atmosphere & Biodiversity & Land & Freshwater & Sea And Coastal Area & CR \\
\hline Group decision & $41.0 \%$ & $12.9 \%$ & $19.0 \%$ & $14.7 \%$ & $12.3 \%$ & 0.007 \\
\hline
\end{tabular}

Table 9. Aggregated priorities based on sub-criteria of Social

\begin{tabular}{ccccccc}
\hline & Poverty & Education & Health & Governance & Demographic & CR \\
\hline Group decision & $9.4 \%$ & $32.4 \%$ & $28.0 \%$ & $15.7 \%$ & $14.4 \%$ & 0.037 \\
\hline
\end{tabular}

Table 10. Aggregated priorities based on sub-criteria of Economic

\begin{tabular}{lcccc}
\hline & $\begin{array}{c}\text { Economic } \\
\text { Development }\end{array}$ & $\begin{array}{c}\text { Global Economic } \\
\text { Partnership }\end{array}$ & $\begin{array}{c}\text { Consumption and } \\
\text { Production Pattern }\end{array}$ & CR \\
\hline Group decision & $58.3 \%$ & $13.3 \%$ & $28.4 \%$ & 0.020 \\
\hline
\end{tabular}

Step 7: Calculate global priorities

Finally, equation (9) is applied to calculate global priorities. The global priorities for all sub-criteria are presented in Figure 2. 


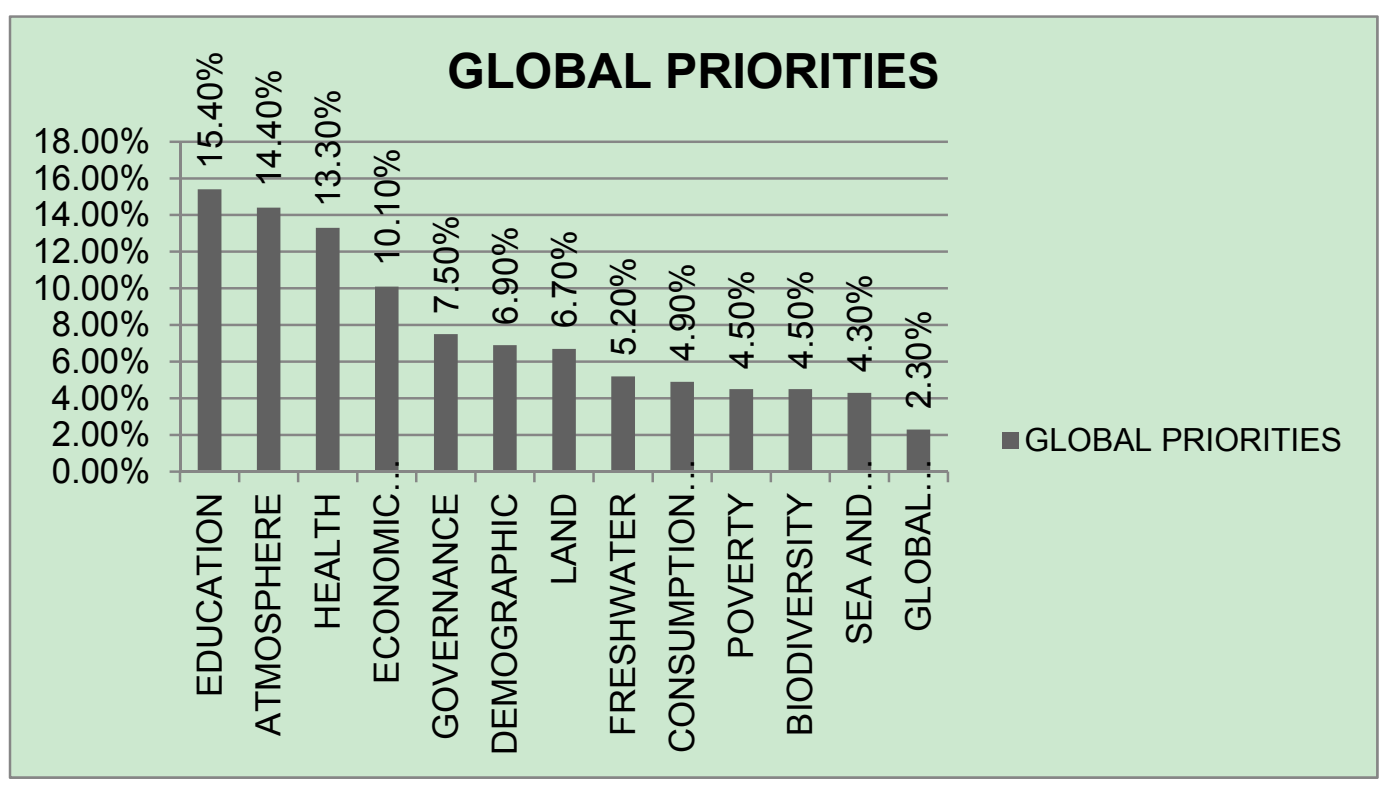

Figure 2. Global priorities of group result

The group decision making of AHP suggests that 'Education' is the most important sub-criteria for development at Setiu Wetlands Terengganu. The next important criteria is 'Atmosphere' followed by 'Health'. Interestingly, 'Global economic partnership' is the least important sub-criteria for this community. The fishermen community doesn't seem too bothered about the world economic development and partnership.

\section{Conclusion}

Rapid economic growths in all parts of the world have been witnessing the importance of the sustainability concept in future development planning. Proper planning of sustainable development is more important in cases of underprivileged communities, especially in developing countries. In this context, investigation of sustainable development of a specific group of communities should gain extreme attention. Various approaches are available for sustainable development assessment ranging from typical surveys to intelligent based methods. The decision making method, AHP has been used in this investigation to prioritize thirteen sub-criteria of sustainable development in the remote underdeveloped Setiu Wetlands Terengganu. The unique feature of the analytic hierarchy process includes the development of pairwise comparison matrices and utilization of weighted geometric mean in aggregation of group decision making. The group decision makers suggest that the sub-criteria of education, the atmosphere and health are the three preferred sub-criteria in this case study. The global priorities of education, the atmosphere and health are obtained as $15.40 \%, 14.40 \%$ and $13.30 \%$ respectively. The results support the contention that education is the utmost important sub-criteria for the fishermen communities. However, the case study reported in this article has not been supported by validation analysis. Sensitivity analysis and comparative studies are among the potential validation analysis that could be suggested for future research direction.

\section{Acknowledgments}

The authors would like to extend a deep appreciation to the Universiti Malaysia Terengganu for providing financial support under the Niche Research Grant Scheme (NRGS). This paper is an output of the NRGS project with vote number NRGS/2015/53131/7.

\section{References}

Abba, A. H., Noor, Z. Z., Yusuf, R. O., Din, M. F. M., \& Hassan, M. A. A. (2013). Assessing environmental impacts of municipal solid waste of Johor by analytical hierarchy process. Resources, Conservation and Recycling, 73, 188-196. Retrieved from http://www.sciencedirect.com/science/article/pii/S0921344913000049.

Al-Atawi, A. M., Kumar, R., \& Saleh, W. (2016). Transportation sustainability index for Tabuk city in Saudi Arabia: An analytic hierarchy process. Transport, 31(1), 47-55. Retrieved from http://www.tandfonline.com/doi/abs/10.3846/16484142.2015.1058857. 
Aldegheishem, A. (2014). Evaluating the Urban Sustainable Development on the Basis of AHP: A Case Study for Riyadh City. Journal of Sustainable Development, 7(2), 113. http://dx.doi.org/10.5539/jsd.v7n2p113

Alonso, L. (2006). Consistency in the analytic hierarchy process: a new approach. International Journal of Uncertainty, Fuzziness and Knowledge based systems, 14(4), 445-459. http://dx.doi.org/10.1142/S0218488506004114.

Aminbakhsh, S., Gunduz, M., \& Sonmez, R. (2013). Safety risk assessment using analytic hierarchy process (AHP) during planning and budgeting of construction projects. Journal of safety research, 46, 99-105.

Azmi, M. A. A., \& Romle, A. R.(2015). Sustainable Development: Development for a Sustainable Future. A Case of Putrajaya Green City. Australian Journal of Basic \& Applied Sciences, 9(14), 30-34.

Choi, H. S., \& Ahn, K. H. (2013). Assessing the sustenance and evolution of social and cultural contexts within sustainable urban development, using as a case the MAC in South Korea. Sustainable City \& Society, 6, 5156.

Cuadrado, J., Zubizarreta, M., Rojí, E., Larrauri, M., \& Álvarez, I. (2016) Sustainability assessment methodology for industrial buildings: three case studies. Civil Engineering and Environmental Systems, 33(2), 106-124.

Escobar, M. T., \& Moreno-jiménez, J. M. (2007). Aggregation of individual preference structures in AHP-group decision making. Group Decision and Negotiation, 16(4), 287-301.

Forman, E., \& Peniwati, K. (1998). Aggregating individual judgments and priorities with the analytic hierarchy process. European journal of operational research, 108(1), 165-169.

Ihlen, Ø., \& Roper, J. (2014). Corporate reports on sustainability and sustainable development: 'We have arrived' Sustainable Development, 22, 42-51.

Jalil, M. A. (2010). Sustainable development in Malaysia: A case study on household waste management. Journal of Sustainable Development, 3(3), 91-102. http://dx.doi.org/10.5539/jsd.v3n3p91.

Malaysia Productivity Corporation. (2010). Sustainable Development Initiatives in Malaysia.

Parkin, S., Sommer, F., \& Uren, S. (2003). Sustainable development: understanding the concept and practical challenge. Proceedings of the ICE-Engineering Sustainability, 156(1), 19-26.

Prakash, M., Shukla, R., Chakraborty, A., \& Joshi, P. K. (2016). Multi-criteria approach to geographically visualize the quality of life in India. International Journal of Sustainable Development and World Ecology, 1-13. Article in Press.

Saadatian, O., Lim, C.H., Mat, S., Sopian, K., Dalman, M., \& Salleh, E. (2011). Sustainable development in Malaysia-planning and initiatives. Recent research in chemistry, biology environment and culture, 138-143.

Saaty, R. W. (1987). The analytic hierarchy process—-what it is and how it is used. Mathematical Modelling, 9(3), 161-176.

Saaty, T. (1977). A scaling method for priorities in hierarchical structures. Journal of Mathematical Psychology, $15,234-281$.

Saaty, T. L. (1980). The Analytic Hierarchy Process. New York, McGraw-Hill.

Saaty, T. L. (2008). Decision making with the analytic hierarchy process. International Journal of Services Sciences, 1(1), 83-98.

Shen, L., Muduli, K., \& Barve, A. (2015). Developing a sustainable development framework in the context of mining industries: AHP approach. Resources Policy, 46, 15-26.

The Brundtland Report. (1987). Our Common Future: Report of the World Commission for Environment and Development.

United Nation Department of Economic and Social Affairs. (2006). Indicators of Sustainable Development: Guidelines and Methodologies. Commission on Sustainable Development, New York, USA.

Veisi, H., Liaghati, H., \& Alipour, (2016). A.developing an ethics-based approach to indicators of sustainable agriculture using analytic hierarchy process. Ecological Indicators, 60, 644-654.

Verma, R., Koul, S., \& Pai, S. S. (2016).Identifying profitable clientele using the analytical hierarchy process. International Journal of Business and Systems Research, 10(2-4), 220-237. http://dx.doi.org/10.1504/IJBSR.2016.075758 
Yagmur, L. (2016) Multi-criteria evaluation and priority analysis for localization equipment in a thermal power plant using the AHP. Energy, 94, 476-482.

\section{Copyrights}

Copyright for this article is retained by the author(s), with first publication rights granted to the journal.

This is an open-access article distributed under the terms and conditions of the Creative Commons Attribution license (http://creativecommons.org/licenses/by/4.0/). 